www.jmscr.igmpublication.org

Impact Factor 5.84

Index Copernicus Value: 83.27

ISSN (e)-2347-176x ISSN (p) 2455-0450

crossref DOI:_https://dx.doi.org/10.18535/jmscr/v5i6.105

Journal Of Medical Science And Clinical Research

IGM Publication

An Official Publication of IGM Publication

\title{
Study on Clinical and Neuroradiological Profile on Patients of Optic Neuritis in Central India
}

\author{
Authors \\ Prof. Dr T.N. Dubey, Ankit Gupta
}

\begin{abstract}
Introduction: Optic neuritis $(O N)$ is an acute inflammatory disorder of the optic nerve. The disease is characterized by unilateral or bilateral acute diminuition of vision, often accompanied by periocular pain maximally associated with eye movements. The majority of cases are idiopathic in origin. This study was undertaken to evaluate the clinical, neuroradiological, electrophysiological profile on patients of optic neuritis in context of various studies.

Materials: The study is an observational study. The study was carried out in OPD patients and admitted patients in department of medicine and department of Ophthalmology, Gandhi Medical College, Bhopal and and associated Hamidia Hospital Bhopal (M.P.).Patients presenting with unilateral or bilateral diminuition of vision less than 4 weeks, presence of relative afferent pupillary defect, dyschromatopsia and normal or swollen optic disc on fundus examination were included in this study. Optic neuropathies like ischemic, toxic, hereditary, compressive and patients under age of 15 years were excluded from study. All patients were subjected to history, clinical examination, visual evoked potential (VEP), MRI brain with orbit.

Observations: 75 eyes of 61 patients were examined. Mean age was 35.29 years .Female preponderance was seen(65.5\%). All patients presented with diminuition of vision less than 4 weeks, and defective colour vision. Bilateral involvement seen in 14 patients (23\%). Papillitis (58\% of eyes) was most common fundus finding. Prolonged P100 latency was seen in 44 patients (72\%) on VEP.MRI Brain showed intracranial demyelination in 23patients(38\%).MRI Orbit showed abnormal findings in $77 \%$ patients

Conclusions: Majority of patients of Optic neuritis of Central India presented with poor visual acquity. Papillitis is frequently seen in patients. Prolonged P100 latency is most common finding seen on VEP. Therefore, VEP, MRI Brain with Orbit is highly recommended in patients of ON for proper management. Clinical profile of $O N$ in Central India patients is different from that seen in Western population.

Keywords: Optic neuritis,multiple sclerosis, relative afferent papillary defect, visual evoked potential.
\end{abstract}

\section{Introduction}

Optic neuritis $(\mathrm{ON})$ is an acute inflammatory disorder of the optic nerve. The disease is characterized by unilateral or bilateral sudden loss of vision, often accompanied by periocular pain maximally associated with eye movements. The majority of cases are idiopathic in origin. However, demyelination, specifically multiple sclerosis (MS), is reported to be the most common etiology in the Western literature. In India and other Asian countries the incidence of MS is reported to be low. It may be associated with metabolic, nutritional, infections or degenerative diseases. The prognosis of optic neuritis in general is good. It is considered that prognosis of retrobulbar neuritis is better than papillitis, 
unilateral better than bilateral and also depends upon the severity of the disease at the time of presentation. The clinical profile of $\mathrm{ON}$ in Indian patients is different from that in the Western population. Most cases of acute demyelinating optic neuritis occur in women (two-thirds) and typically develop in patients between the ages of 20 and 40 The incidence of optic neuritis is highest in populations located at higher latitudes, in the northern United States and western Europe, and is lowest in regions closer to the equator. In the United States, studies have estimated the annual incidence of optic neuritis to be as high as 6.4 per 100,000. In the United States, optic neuritis occurs more frequently in whites than blacks (In Asia, optic neuritis is proportionately more common relative to the incidence of multiple sclerosis than in the United States or western Europe.

\section{Objectives}

1. To evaluate the clinical profile on patients of optic neuritis in context of various studies

2. To evaluate the neuroradiological profile on patients of optic neuritis in context of various studies.

3. To evaluate the electrophysiological profile on patients of optic neuritis in context of various studies.

\section{Materials and Methods}

The study was an observational study. The study was carried out in OPD patients and admitted patients in department of medicine and department of Ophthalmology, Gandhi Medical College, Bhopal and and associated Hamidia Hospital Bhopal (M.P.) for which approval was taken from ethical committee of the institution and study was conducted between March 2015 to August 2016.The study group included persons who were diagnosed on basis of history, clinical examination, fundus examination, neuroimaging and electrophysiological study.

Informed consent was taken from every patient.

\section{Inclusion Criteria}

Patient presenting with

1. Sudden unilateral or bilateral decrease of vision less than 4 weeks.

2. Presence of relative afferent pupillary defect.

3. Dyschromatopsia

4. Normal or swollen optic disc on fundus examination.

\section{Exclusion Criteria}

1. Patient less than 15 yrs.

2. Optic neuropathies such as ischaemic, toxic, hereditary, compressive

All patients were subjected to routine and special investigations to ascertain

clinical and neuroradiological profile on patients of optic neuritis.

1. History

2. Clinical Examination

3. Fundus examination

4. Visual acquity through snellen "s visual chart

5. Pupil examination

6. Colour vision through Ishihara Charts.

7. Visual evoked potential

8. MRI brain with orbit.

9. Hemogram, total and differential leucocyte count, ESR

10. Chest X ray

All these investigations were done before treatment was started for optic neuritis.

In the study, detailed history was obtained in every patients, which documented onset of visual loss, duration, association with pain, any previous attack and history of any other neurological symptoms.

Then all patients underwent Neuroimaging, to detect intracranial pathology and orbital pathology.

Visual evoked potential study was done in all patient to ascertain optic nerve functioning.

After complete work up patients were distributed into groups based on age, sex, neuroimaging findings and electrophysiological findings. 
Clinical examination included pupil examination, fundus examination, colour vision with ishihara test plates was done.

An inability to read any one of Ishihara test plates was considered abnormal.

Then all patients underwent Neuroimaging, to detect intracranial pathology and orbital pathology.

Visual evoked potential study was done in all patient to ascertain optic nerve functioning. Hemogram, total and differential leucocyte count chest $\mathrm{X}$ ray were obtained in all cases.

After complete work up patients were distributed into groups based on age, sex, neuroimaging findings and electrophysiological findings.

\section{Results}

Table - 1 (Sex Distribution)

\begin{tabular}{|l|c|c|c|}
\hline & \multicolumn{3}{|c|}{ Sex Distribution } \\
\hline Sex & Number & Percentage(\%) & \\
\hline Male & 21 & 34 & \\
\hline Female & 40 & 66 & \\
\hline Total & 61 & 100 & \\
\hline
\end{tabular}

Table - 2 (Age Distribution)

\begin{tabular}{|l|c|c|}
\hline \multicolumn{2}{|l|}{ Age Distribution } \\
\hline Age & No. of Patient & Percentage(\%) \\
\hline $15-20$ & 7 & 11 \\
\hline $21-40$ & 39 & 64 \\
\hline $41-60$ & 12 & 20 \\
\hline $61-80$ & 3 & 5 \\
\hline Total & 61 & 100 \\
\hline
\end{tabular}

The study group included 61 patients of optic neuritis. There were 21(34\%) male and 40(66\%) female patients. The ratio of female to male is 1.9:1. The age distribution ranged from as low as 20 years to upto 80 years, with the majority being females of 20-40 years age group.

All patients presented with decrease in vision and colour vision.

Table - 3 (Visual Acquity In Patients )

\begin{tabular}{|l|c|c|c|}
\hline & \multicolumn{3}{|c|}{} \\
\hline Visual acquity & $\begin{array}{c}\text { Total No. of } \\
\text { Eyes }\end{array}$ & Percentage(\%) & \\
\hline Better than 6/60 & 13 & 17 & \\
\hline $6 / 60-$ HM+ & 36 & 48 & \\
\hline PL+ & 24 & 32 & \\
\hline PL- & 2 & 3 & \\
\hline Total & 75 & 100 & \\
\hline
\end{tabular}

Most eyes had initial visual acuity very poor in 24 eyes $(32.3 \%)$ visual acquity was reduced to perception of light and in 3\% (2 patients) perception of light was absent. 36 patients (48\%) have visual acquity between $<6 / 60$ to Hand movement + . Only 13 patients $(17 \%)$ patients visual acquity was good ( $>6 / 60$ or better)

Table - 4 (Fundus Findings in Patients)

\begin{tabular}{|l|c|c|l|}
\hline & \multicolumn{3}{|c|}{} \\
\hline $\begin{array}{l}\text { Fundus } \\
\text { examination }\end{array}$ & Number of eyes & Percentage(\%) & \\
\hline Papillitis & 44 & $58.60 \%$ & \\
\hline Normal & 31 & $41.40 \%$ & \\
\hline Total & 75 & 100 & \\
\hline
\end{tabular}

In this study 75 eyes were examined for fundus. 44 eyes (58.6\%) showed optic disc were hyperemic or blurring of disc margin (Papillitis) while $31(41.4 \%)$ eyes fundus examination were normal

Tables - 5 (VEP Findings In Patients)

\begin{tabular}{|l|c|c|}
\hline VEP Findings & Number & Percentage(\%) \\
\hline P100 PROLONGED & 44 & 72 \\
\hline Decreased amplitude & 14 & 23 \\
\hline Absent Wave form & 3 & 5 \\
\hline
\end{tabular}

In this study VEP was done in 61 patients. 44 (72\%) patients presented with prolonged P100 latencies. 14 patients (23\%) had decreased amplitude. While 3 patients $(5 \%)$ had absent waveform

Table - 6 (MRI Brain Findings)

\begin{tabular}{|l|c|c|}
\hline MRI Brain & Number & Percentage(\%) \\
\hline Demyelinating & 23 & 38 \\
\hline Normal & 38 & 62 \\
\hline Total & 61 & 100 \\
\hline
\end{tabular}

MRI brain was done in 61 patients. Out of which $23(38 \%)$ patients had demyelinating lesions in brain while 38 patients had normal MRI Brain.

\section{Discussion}

Optic neuritis is an acute inflammation disorder of optic nerve. This is characterised by unilateral or bilateral loss of vision often accompanied by periocular pain on eye movements. This is a 
hospital based observational study of patients of optic neuritis. The majority of cases are idiopathic in origin. However demyelination is reported to be most common etiology in Western literature. In India and other Asian countries, incidence of MS is reported to be low. Moreover, various studies from South East Asia have documented difference in etiology, clinical presentation, prognosis of ON compared to Western population. Moreover, there is no study undertaken to know the clinical profile in patients of optic neuritis in central India and hence it was decided to undertake this study to analyze clinical profile in patients of optic neuritis in Central India in context to various studies. In this study, 61 patients were included after diagnosed on basis of history, clinical examination and investigational work up was done. These patients underwent neuroimaging to detect intracranial and orbital pathology and VEP to detect electrophysiological profile. After complete workup patient was distributed in groups based on age, sex, symptoms, clinical signs and neuroimaging and electrophysiological study. Hemograms, total leucocyte count, differential count, Chest X ray was obtained in each case and was normal.

\section{Parameters of study}

Sex: In present study,61 patients of optic neuritis were included, total 40 were females and 21 males. There was female preponderance with female to male ratio 1.9:1. This was in agreement with study of ONTT Which showed female to male ratio 3:1, another study of Saxena et al showed female to male ratio 2.2:1, Sreenivasulu et al study showed female to male ratio 1.3:1, Shariah et al study of Malaysia showed female to male ratio of 2.1:1 while Jain et al showed contrasting feature of male to female ratio2:1.

Age: Optic neuritis commonly occurs in age between $20 \mathrm{yrs}$ to $50 \mathrm{yrs}$. In present study $64 \%$ patients were between age group of 21-40 years.

Most common age group affected was 15-60 years. Mean age was 35.29 years which was comparable to study of saxena et al which showed mean age27.6+8.8 years(15-58 years) while ONTT study showed age group 18-46 years as most common age group.

Visual acquity: In present study, most of eyes had very poor visual acquity at presentation. In 24 eyes (32\%) visual acquity was reduced to perception of light and in 3\% perception of light was absent. our study revealed that $83 \%$ had visual acquity $6 / 60$ or less .Jain et al study showed $13 \%$ had good visual acquity while study done by Shariah et al of Malaysia showed $73 \%$ had visual acquity of $6 / 60$ or worse .C. sreenivasulu et al study showed that $86 \%$ patients had partial loss of vision while $14 \%$ had complete loss of vision.

Fundus examination: In present study 75 eyes were examined for fundus.44 eyes (58.6\%) showed papillitis whereas 31 eyes showed normal fundus or retrobulbar neuritis. Study done by saxena et al of AIIMS showed 53.5\% patients had papillitis and $46.5 \%$ patient had normal fundus. Study of Shariah et al showed $65 \%$ patients had papillitis. Jain et al study showed $55.8 \%$ of patients showed papillitis on fundus examination. In contrast to above findings, C.Sreenivasulu et al study showed $26.7 \%$ patient have papillitis, ONTT study showed $65 \%$ normal fundus or retrobulbar neuritis. Findings were in consistent with Asian studies while ONTT study showed western data.

VEP Study: In this study VEP was done in 61 patients.44 patients (72\%) showed prolonged P100 latencies in VEP,14 patients (23\%) had decreased amplitude, while 3 patients $(5 \%)$ had absent waveform. While study done by C.sreenivasulu et al of Kurnool showed $65 \%$ patients had prolonged P100 latencies, Suha Mihail Al Ejailat et al of UK showed $90 \%$ patients had prolonged latencies on VEP study. In present study $23 \%$ patients had decrease amplitude which was comparable to $28 \%$ of patients with decrease amplitude in a study done by, Suha Mihail Al Ejailat et al of UK

MRI Brain and Orbit: In this study, 61 patients underwent MRI Brain and orbit. Intracranial demyelination was seen in $38 \%$ of patients while 
rest MRI brain were normal This is in consistency of study done by C,sreenivasulu et al of Kurnool showed $38 \%$ of periventricular white matter intensities. While Suha Mihail Al Ejailat et al of UK showed 28 percent of demyelinating lesions. Saxena et al study showed $37.5 \%$ patient showed intracranial demyelination MRI orbit showed 77 percent were abnormal with increased signal intensity of optic nerve or intracanalicular fluid rim gadolinium enhancement in present study while study done by Kupersmith et al showed 95\% MRI orbital abnormality

\section{Conclusion}

Optic neuritis is a common cause of acute onset of diminuition of vision in patient presenting to hospital. It is frequently associated with multifocal pathology such as multiple sclerosis in western countries while more association is seen with neuromyelitis optica (NMO) or myelitis in Asian countries. Thus patients need thorough clinical, radiological as well as electrophysiological evaluation. Majority of patients of optic neuritis are female with majority belonging to middle age group (21-40 years) Diminiuition of vision is most common complaint and in majority of patients and this is associated with periocular pain although one-fifth of patients do not have ocular pain. Prolong P100 latency is the most common abnormality seen on VEP which suggest demyelination in pathology. Intracranial demyelination is seen in upto one-third of patients of optic neuritis on MRI and MRI is needed in these patients for appropriate diagnosis and management

\section{References}

1. Beck RW, Cleary PA. Optic Neuritis Study G. Optic neuritis treatment trial: one-year follow-up results.Arch Ophthalmol. 1993; 111(6):773-5. ]

2. Jain IS, Munjal VP, Dhir SP, Gangwar DN. Profile of optic neuritis in Chandigarh and surrounding areas. Indian J Ophthalmol. 1980;28:195-200.
3. de la Cruz J, Kupersmith MJ. Clinical profile of simultaneous bilateral optic neuritis in adults. Br J Ophthalmol 2006; 90:551.

4. Kupersmith MJ, Gal RL, Beck RW, Xing D, Miller N. Optic Neuritis Study Group. Visual function at baseline and 1 month in acute optic neuritis: predictors of visual outcome. Neurology. 2007;69:508-1

5. Saxena R, Phuljhele $\mathrm{S}$, Menon V, Gadaginamath S, Sinha A, Sharma P. Clinical profile and short-term outcomes of optic neuritis patients in India. Indian J Ophthalmol 2014;62:265-7

6. Clinical Profile and Aetiology of Optic Neuritis in Hospital Universiti Sains Malaysia - 5 Years Review Ismail Shatriah, Wan Hazabbah Wan Hitam, Muhd-Nor Nor-Idahriani, Daud Jakiyah, Embong Zunaina, Med J Malaysia Vol 67 No 2 April 2012

7. A clinical case study on short term visual outcome of optic neuritis with IV Methyl prednisolone C.Sreenivasulu, K. vidyasagar. Indian journal of applied research volume 6 issue 2 February 2016 387-389

8. The role of magnetic resonance imaging and visual evoked potential in management of optic neuritis .Suha mikail al -ejailat, Mousa victor Al-madani senior Pan African medical journal 2014

9. Lim SA, Goh KY, Tow S, Fu E, Wong TY, Seah A, et al. Optic neuritis in Singapore. Singapore Med J 2008;49:667-71.

10. Liu GT. Visual loss: optic neuropathies. In: Neuro-Ophthalmology: Diagnosis and Management, Liu GT, Volpe NJ, Galetta SL (Eds),WB Saunders,Philadelphia 2001.

11. Wray, SH. Optic neuritis. In: Principles and Practice of Ophthalmology, Albert, DM, Jakobiec, FA (Eds), WB Saunders, Philadelphia 1994. p.2539.

12. The clinical profile of optic neuritis. Experience of the Optic Neuritis 
Treatment Trial. Optic Neuritis Study Group. Arch Ophthalmol 1991; 109:1673.

13. Percy AK, Nobrega FT, Kurland LT. Optic neuritis and multiple sclerosis. An epidemiologic study. Arch Ophthalmol 1972; 87:135.

14. Rodriguez M, Siva A, Cross SA, et al. Optic neuritis: a population-based study in Olmsted County, Minnesota. Neurology 1995; 45:244.

15. Phillips PH, Newman NJ, Lynn MJ. Optic neuritis in African Americans. Arch Neurol 1998; 55:186.

16. Wakakura M, Minei-Higa R, Oono S, et al. Baseline features of idiopathic optic neuritis as determined by a multicenter treatment trial in Japan. Optic Neuritis Treatment Trial Multicenter Cooperative Research Group (ONMRG). Jpn J Ophthalmol 1999; 43:127.

17. von Graefe A. Ueber complication von sehnervenentzundung mit gehirnkrankheiten. Archiv Ophthalmologie 1860;1: 58-71.

18. Nettleship E. On cases of retro-ocular neuritis. Trans Ophthal Soc UK 1884;4:186-226.

19. Balcer LJ. Clinical practice. Optic neuritis. N Engl J Med 2006; 354:1273.

20. Foroozan R, Buono LM, Savino PJ, Sergott RC. Acute demyelinating optic neuritis. Curr Opin Ophthalmol 2002; 13:375.

21. Frohman EM, Frohman TC, Zee DS, et al. The neuro-ophthalmology of multiple sclerosis. Lancet Neurol 2005; 4:111.

22. Arnold AC. Evolving management of optic neuritis and multiple sclerosis. Am J Ophthalmol 2005; 139:1101.

23. Rosati G. The prevalence of multiple sclerosis in the world: an update. NeurolSci2001;22:117-39 